\title{
Ambivalence toward a country and consumers' willingness to buy emblematic brands: The differential predictive validity of objective and subjective ambivalence measures on behavior
}

\author{
Cristel Antonia Russell • Dale W. Russell • Jill Klein
}

Published online: 3 November 2010

(C) The Author(s) 2010. This article is published with open access at Springerlink.com

\begin{abstract}
Previous country-of-origin research has treated opinions of countries as either positive or negative, even though people may in fact hold conflicting opinions about countries. The extant literature on ambivalence suggests that the coexistence of positive and negative opinions of a country should increase avoidance of objects associated with that country, above and beyond the effects of mere positivity or negativity. Data collected from French consumers who varied in degrees of ambivalence toward the US reveal that ambivalence, measured indirectly through consumers' coexisting positive and negative views, is indeed negatively related to consumers' willingness to buy emblematic American brands. The findings highlight the latent nature of ambivalence, the difficulty of assessing the subjective experience of the ambivalence state, and the importance and practicality of using indirect measures.
\end{abstract}

Keywords Country-of-origin $\cdot$ Ambivalence $\cdot$ Brand image $\cdot$ Indirect measure $\cdot$ Latent construct

This research examines how ambivalence toward a country relates to consumers' willingness to buy (WTB) brands emblematic of that country. Previous country-oforigin $(\mathrm{CoO})$ research has treated country attitudes as a univalent construct, ranging from negative to positive. The extant literature finds that positive/negative country

C. A. Russell ( $\square)$

University of Auckland Business School, 12 Grafton Road, Auckland 1142, New Zealand

e-mail: c.russell@auckland.ac.nz

D. W. Russell

University of California, Berkeley, 1995 University Avenue, Suite 450, Berkeley, CA 94704, USA

e-mail: dwrussell@berkeley.edu

J. Klein

Melbourne Business School, 200 Leicester St, Carlton, VIC 3053, Australia

e-mail: jillklein5@gmail.com 
attitudes can lead consumers to make positive/negative inferences about product quality (Hong and Wyer 1989, 1990; Johansson et al. 1985; Li and Wyer 1994), and this is reflected in product purchases. Consistent with this univalent approach, the animosity model of foreign product purchase (Klein et al. 1998) and subsequent studies (e.g., Klein 2002; Nijssen and Douglas 2004; Riefler and Diamantopoulos 2007; Russell and Russell 2006) have documented that negative views of a country, emanating from past military, economic or political conflicts, negatively affect consumers' willingness to buy a country's products. The literature has not yet directly investigated what happens when consumers harbor both positive and negative views of a country and especially how ambivalence - the coexistence of both positive and negative views of the country-relates to consumers' WTB brands from that country. Answering these questions requires a turn to the ambivalence literature.

\section{Ambivalence}

\subsection{Defining ambivalence}

Although attitudes have typically been conceptualized and measured along a bipolar continuum ranging from negative to positive, people often hold inconsistent beliefs or feelings about an object or issue, some positive and some negative (Breckler 1994). The evaluative inconsistency toward an attitude object is referred to as ambivalence (Katz 1981). In 1911, psychiatrist Eugen Bleuler introduced the concept to psychology in order to capture pathological forms of loving and hating the same object. Ambivalence was quickly recognized as a prevalent experience in the everyday life of normal people, and indeed the marketplace yields many shopping situations and purchase options that are inherently both positive and negative (Otnes et al. 1997). People also frequently hold inconsistent evaluations about consumption behaviors, such as drinking alcohol, eating low fat diets, or even driving a SUV, toward which they harbor both positive and negative views (Locke and Braun 2009).

Being ambivalent about an attitude object is different from being indifferent about it (Kaplan 1972). In fact, research on ambivalence has spawned from the realization that traditional measures of attitudes could not distinguish between people who are conflicted between two sides of an issue (ambivalence) and people who do not care either way (indifference); both would indicate the middle scale point on common bipolar unidimensional scales rating from weak to strong. This led to the suggestion that positive and negative opinions about an object should be assessed separately, and indeed, across many studies, positive and negative evaluations were found to cluster separately and form two factors with a small negative correlation (Thompson et al. 1995) and, in some domains, such as racial attitudes, no correlation at all (e.g., Has et al. 1991).

\subsection{Measuring ambivalence}

Much research has been conducted to find an appropriate way to measure ambivalence, and multiple models have been developed (Kaplan 1972). Approaches 
to measuring ambivalence include both subjective and objective measures. The socalled subjective perception of ambivalence (or felt ambivalence) is simply measured by asking individuals directly how conflicted they are about an issue/topic (Tormala and DeSensi 2008). There are some issues with this approach. First, previous research has found that asking people whether they feel ambivalent can be misunderstood as a question about feeling indecisive or uncertain, thus not accurately capturing the actual subjective experience of ambivalence and leading to poor predictive validity (Larsen et al. 2001). Second, a large body of research, especially in the area of racial attitudes, has demonstrated that people may hold ambivalent views about an issue but be unable to explicitly express those views as divided because the conflict is unconscious (Hass et al. 1992; Katz and Hass 1988; Maio et al. 2000). As such, people may not be able to accurately make a direct and conscious assessment of their ambivalence (Hass et al. 1992).

Therefore, another approach, referred to as the objective approach, relies on measuring the actual positive and negative components and deriving ambivalence scores as a function of the two components. This more commonly used approach allows an assessment of the independent roles of the positive (or pro-issue) and negative (or anti-issue) components of one's attitude and to further isolate the role of ambivalence (Federico 2006; Maio et al. 2000). The simplest mathematical computation of objective ambivalence is the cross-product of the positive and negative components (Hass et al. 1992). Another computation, the gradual threshold model (GTM) of ambivalence, was proposed by Priester and Petty (1996) as a function of dominant and conflicting reactions, the former referring to whichever of the positive or negative reactions is greater and the latter to whichever is lesser. Since this GTM of ambivalence computation has been found to be superior to all others for inferring the experience of ambivalence (Priester and Petty 1996, see also Priester et al. 2007), this model will be used in this research as an indirect, objective measure of ambivalence. Both subjective and objective ambivalence measures will be utilized as recommended by Federico (2006), although, as in previous research, the correlation is expected to be low (between 0.2 and 0.4; Newby-Clark et al. 2002; Priester and Petty 1996; Thompson et al. 1995).

\subsection{Coping with ambivalence}

In general, it seems people do not enjoy ambivalence. Research on cognitive dissonance (e.g., Festinger 1957) and balance theory (Heider 1946) both suggest that individuals try to reduce the experience of inconsistent attitudes. In the context of consumer behavior, where the focus has been on affective ambivalence, or the coexistence of mixed emotions (Lau-Gesk 2005; Williams and Aaker 2002), one particularly relevant finding is that one way consumers cope with conflicting feelings is by resisting purchasing the items that generate those conflicts (Otnes et al. 1997). When faced with a difficult decision, people avoid making choices altogether (Luce 1998). Thus, the literature to date supports the view that, as ambivalence increases, people are more likely to avoid the objects that create this ambivalence.

Research has shown that, even when people are not conscious of latent feelings, these feelings may manifest themselves indirectly and in symbolic ways (Banaji and Greenwald 1994; Kinder and Sears 1981) in consummatory responses involving 
basic behavioral approach/withdrawal (Amodio and Devine 2006), such as purchase behaviors. For instance, Ouellet (2007) found that consumers' latent racist views manifest themselves in lower WTB products perceived as originating from the dominant minority ethnic group. In a similar fashion, consumers may not be conscious of their ambivalent feelings toward a country, and yet this ambivalence may manifest itself as an impulsive motivational tendency to avoid objects associated with that country (Back et al. 2009) and this would be reflected in lower WTB emblematic brands from that country. Because avoidance behaviors are activated automatically, through impulsive processes (Strack and Deutsch 2004), predictions of these avoidance tendencies should be based on an objective, indirect, assessment of the coexistence of positive and negative views of a country (Back et al. 2009). Thus, both objective and subjective ambivalence are measured to assess their predictive validity of the WTB emblematic brands.

\section{Emblematic brands}

This research focuses on the relationship between country ambivalence and the consumption of emblematic brands from that country. It is well established that a product's $\mathrm{CoO}$ influences consumers' evaluations. $\mathrm{CoO}$ research has generally examined how a country's image (e.g., concerning workmanship) is projected onto the features of products produced by that country (e.g., Johansson 1989; Papadopoulos and Heslop 1993). In general, the research has found that images of the manufacturing nation have a substantial impact on consumers' evaluations of product quality (e.g., Papadopoulos and Heslop 1993; Hong and Wyer 1989). Yet, research on $\mathrm{CoO}$ effects has mainly focused on durable products and studied whether and how $\mathrm{CoO}$ affects consumers by exposing them to information about products "made in" a particular country (e.g., Gürhan-Canli and Maheswaran 1994). Surprisingly, $\mathrm{CoO}$ studies to date have relied on effects at the product or category level, but not at the level of the brand.

Yet brands can become emblematic of a particular country. Brand origin is sometimes referred to as "the place, region or country to which the brand is perceived to belong by its target consumers" (Thakor 1996, p. 7). In many cases, brands are integrally linked to a country, the country becoming part of the essence of its emblematic brands and, vice versa, the brands becoming part of the essence of the country (Aaker 1991). For example, French perfume brands are French not only in their development and manufacture but also in their symbolic essence; one who wears a French perfume may be expressing an affiliation with French style and sophistication (Leclerc et al. 1994; Peabody 1985). Some brands become icons of their country, regardless of whether they are actually produced there (Holt 2004). $\mathrm{CoO}$ evaluations, therefore, should be viewed as part of a larger brand image construct that also encompasses symbolic and emotional components related to historical and developmental linkages (Pharr 2005). Research derived from a semiotic perspective of brands has long acknowledged the importance of taking into account all symbolic meanings associated with brands, including their history and cultural heritage, to better understand how their meaning in the eyes of consumers translates into economic value and brand equity (Hatch and Rubin 2006; Holt 2004; 
Ouellet 2007). So far, no research has addressed whether and how consumers' WTB brands emblematic of a given country relates to the ambivalence that they may hold toward the country.

\section{Theoretical framework}

In line with the extant research on the structure of attitudes, it is proposed that the positive and negative dimensions of consumers' views of countries are distinct and some consumers thus harbor both positive and negative views of the country (i.e., they are ambivalent toward the country). Beyond the logical main effects of positivity and negativity toward a country on consumers' brand choices, it is important to account for their interplay and assess how ambivalence toward a country relates to their desire to buy emblematic brands from that country.

Based on previous research relating to how ambivalence affects choices, when people harbor both positive and negative views of a country, the resulting ambivalence should have negative consequences in terms of their WTB brands from that country (Lau-Gesk 2005; Otnes et al. 1997; Williams and Aaker 2002). Even though consumers may not be conscious of their ambivalence, it is expected that ambivalence, independent of positive and negative views toward a country, would be directly and negatively related to their WTB brands from that country. Thus, it is predicted that higher levels of ambivalence will be related to a lower WTB emblematic brands. Further, both direct subjective and objective implicit measures of ambivalence are implemented to best predict WTB.

\section{Methods}

\subsection{Research context}

This research is conducted in the context of the consumption of emblematic American brands in France. The notion of brand origin is particularly important for US multinationals given many brands' strong associations with the American lifestyle. For instance, Goldberg and Baumgartner (2002) found that Thai youth who harbored positive views of the US and were attracted by the American lifestyle were more likely to smoke Marlboro cigarettes, which are symbolic of that lifestyle. The USA, a country toward which people often exhibit conflicting and sometimes counterintuitive views, is a fitting example of ambivalence (Berman 2005; Sardar and Davies 2003). Negative US sentiments are exhibited by millions of people throughout the world (Katzenstein and Keohane 2007; Sardar and Davies 2003), but often these views coexist with feelings of admiration, resulting in an overall mixed opinion (World Public Opinion 2009). Many US corporations are concerned about the impact of anti-American feelings on consumers' purchases and thus worry that their international business interests might be jeopardized (Kuehn 2005). Yet, despite frequent media coverage and corporate concerns, academic research lags in this area and much remains to be examined regarding the relationship between global consumers' opinions of the US and their purchases of American brands (Zogby 
International 2005). France is an ideal setting for this investigation because the relationship between France and the USA has oscillated between friendliness and disdain over the past two centuries (Roger 2005), and it embodies the love-hate attributes of ambivalence (Katz 1981).

\subsection{Exploratory phase of instrument development}

In order to develop the instruments for the main study, 12 in-depth interviews were conducted across France, one third in a major city in the south of France, one third in a rural area of western France, and one third in the Paris region. This process yielded responses from a diverse group, both socioeconomically and demographically, with ages ranging from early 20 s to late $50 \mathrm{~s}$. All participants were told that the purpose of the research was to uncover French people's views and opinions about the USA. The semi-structured interviews began with a general question "Tell me about your opinion of the US," which was followed by the more focused "When you think of the US, what comes to mind?" and "What things do you like or dislike about America?" Then, the conversation was directed into consumption-related topics prompted by "Tell me about American things you might own or buy, and why" and "Tell me about American things you would never own or buy, and why." Finally, participants were asked "What American brands are you most familiar with?" To prevent contamination effects, the order of the questions was alternated so that half the interviews began with consumption questions. Demographic information was collected last.

The transcripts were analyzed thematically. The interview data were categorized into conceptual themes as dimensions emerged during the collection (Spiggle 1994). This process allowed the identification of several aspects of feelings toward the USA. The most salient negative component was political in nature, with respondents commenting on the military presence of the USA in the world and its ties to economic interests and condemning policies in Iraq and in the Middle East in general. Economic issues were also discussed and there were often both positive views expressed about the flexibility associated with free market principles as well as negative views about the costs to society. Admiration for the market-based system was evident in many interviews, especially in reference to the relatively stagnant French job market. The most prevalent topic of discussion was related to cultural aspects, especially in terms of the creativity and innovativeness of many American cultural products, such as television programs, movies, and music. Yet, some respondents interlaced negative feelings about the omnipresence of such products.

Finally, when inquiring about American brands and products, informants identified highly emblematic representations of Americana, such as movies and classic cars, and in the realm of brands, Coca-Cola and Levi's were often mentioned. Overall, the interview data suggested the importance of developing an index of US brand consumption, an issue discussed later.

\subsection{Development of country ambivalence measures}

As discussed previously, ambivalence can be assessed either through objective or subjective measures (Back et al. 2009), and this study used both approaches. To 
develop the objective country ambivalence measure, scale items were derived from the interview transcripts to generate an equal set of positive and negative statements to capture prevalent beliefs about the USA. The measures were pre-tested with a sample of French university students. An invitation to participate in a "study of how French people feel about the United States" was circulated electronically to 850 students at a French public university. Participation was encouraged through the use of lottery for a gift certificate. Of those invited, 291 (180 females) completed the online survey. Respondents rated their degree of agreement with 20 randomly ordered statements (ten positive and ten negative, see "Appendix") on a Likert scale (1-not at all to 7-very much). Following these measures, participants were asked to consider their general opinion about the USA and to indicate the degree to which each of nine adjectives described it on a unipolar scale anchored by not at all (1) and extremely (7). Three adjectives "divided", "ambivalent", and "mixed" were included in the set to provide the subjective measure of felt ambivalence (Cacioppo et al. 1997; Priester and Petty 1996). The order of these nine items was randomized.

Both the positive and negative scales yielded acceptable reliability $(\alpha=0.72$ for both), and as suggested by the literature on ambivalence, the correlation between the positivity and negativity scores was significant but small $(r=-0.23, p<0.05)$ indicating that the two dimensions are distinct. An additional test of discriminant validity was conducted by comparing a structural model where the covariance of the positive and negative factors was set to 1 to a model where it was unconstrained. The unconstrained model provides a significantly improved fit over the constrained one $\left(\Delta \chi^{2}(1)=245.72, p<0.01\right)$, thereby providing evidence of discriminant validity. Two ambivalence scores were created: the objective measure of ambivalence computed based on Priester and Petty's (1996) GTM and yielding scores ranging from -2.00 to $9.23(M=7.09 ; \mathrm{SD}=1.08)$ and the subjective measure computed as the mean on the three items $(M=4.38 ; \mathrm{SD}=1.44)$ of the felt ambivalence scale $(\alpha=0.79)$. The correlation between the objective and subjective measures is significant but small $(r=0.32, p<0.05)$ and in par with previous studies (Thompson et al. 1995; Priester and Petty 1996). This indicates that subjectively reported ambivalence does not necessarily reflect the inner conflict between the positive and negative components of country views and reiterates the potential latent nature of ambivalence and the importance of measuring it through the objective method.

\subsection{Development of the emblematic brand index}

Several issues were taken into consideration during the development of the index of WTB emblematic US brands. First, while CoO studies generally only address a few product categories (Johansson et al. 1985), the index sought to cover a range of categories. Second, the measure should avoid making $\mathrm{CoO}$ obvious. Third, consistent with a formative perspective for index construction (Diamantopoulos and Winklhofer 2001), content validity must be ensured by covering the domain of the construct, including several indicators of WTB across a range of emblematic US brands.

Emblematic brands were selected using the following procedures: Criteria were established in order to select a set of American brands that were known, likely to be consumed by the average consumer, and in competitive product categories. 
Therefore, (1) luxury or service brands were excluded and only brands of common consumer products were used, (2) brands had to be familiar to the population studied, (3) only product categories were included that provided consumers' choices (e.g., no monopolies such as Microsoft), and (4) US brands were indeed perceived as being American. All considered US brands were high revenue generators for American businesses, listed on Interbrand's (2006) top 100 global brands, and providing a range of categories.

Then 24 brands underwent pre-testing on a sample of French public university students. An invitation to participate in a "study about consumption and brands" was circulated electronically to 5,000 students and 825 (468 females) completed the online survey. Ten of the tested brands were non-US brands (also from Interbrand) and were interspersed among the US brands to hide the purpose of the survey. Participants indicated whether they were familiar with each brand (yes/no) and rated the extent to which they perceived each brand as American ( $1=$ not at all American, $7=$ very American). From this process, seven brands were selected to comprise the final US brand index that would serve as a dependent measure in the main study. These seven brands had the highest levels of perceived American-ness (mean rating significantly above 5 on the seven-point scale, all $t$ 's $(820)>3.11, p$ 's $<0.01)$ among those brands that were familiar to over $90 \%$ of those surveyed. As depicted in Table 1, the findings are similar to those from a survey of 1,000 French and US consumers to determine "how closely they associate each brand with America" (GMI 2005).

To develop the index of WTB emblematic brands, the pre-test included two measures of purchase behavior for each of the 24 brands tested. Participants indicated how often they purchase each brand, from 1 (never) to 7 (very often), and how likely they are to purchase each brand in the future, from 1 (not at all likely) to 7 (very likely). Correlations between each pair of measures for the seven emblematic US brands ranged from 0.70 to 0.79 , demonstrating strong reliability.

\section{Main study}

\subsection{Methodology and sample}

Participants in the main study were members of a consumer panel representative of the French population. The data were collected in France in the fall of 2006 via a professional European marketing research company. The company maintains a detailed national panel of consumers by country who have volunteered to partake in research. In France, the panel includes 100,000 participants representative of the national population based on age, sex, socioeconomic status (education and profession), and region. To ensure a range of ambivalence levels, invitations to participate in an online study were sent to the panel members in small increments until a quota of responses $(N=50)$ was obtained of people who were unambivalently positive (mean positivity toward the USA on the ten-item scale $>4$, the mid-point of the scale, and mean negativity $<4$ ), unambivalently negative (negativity $>4$ and positivity $<4$ ), high positive and negative (positivity and negativity both $>4$ ), and low positive and negative 
Table 1 Perception of American-ness

${ }^{\text {a }}$ Denotes brands selected for the US brand index in main study

\begin{tabular}{|c|c|c|}
\hline Brand & $\begin{array}{l}\text { From GMI data in France } \\
(N=1,000 ; 1=\text { not at all, } \\
5=\text { extremely })\end{array}$ & $\begin{array}{l}\text { From preliminary study } \\
\text { in France }(N=825 ; \\
1=\text { not at all, } 7=\text { very })\end{array}$ \\
\hline Coca-Cola $^{a}$ & 4.79 & 6.94 \\
\hline McDonald's $\mathrm{s}^{\mathrm{a}}$ & 4.78 & 6.95 \\
\hline Disney & 4.61 & 6.34 \\
\hline GM & 4.43 & 6.49 \\
\hline Levi's $^{\mathrm{a}}$ & 4.34 & 6.41 \\
\hline $\mathrm{Pepsi}^{\mathrm{a}}$ & 4.33 & 6.41 \\
\hline Nike $^{a}$ & 4.29 & 6.35 \\
\hline Apple & 4.27 & 6.06 \\
\hline $\operatorname{Hein}^{\mathrm{a}}$ & 4.24 & 5.14 \\
\hline GE & 4.07 & 5.96 \\
\hline Ford & 4.00 & 4.97 \\
\hline MTV & 3.93 & 6.47 \\
\hline Budweiser & 3.90 & 5.10 \\
\hline Barbie & 3.89 & 5.63 \\
\hline Kellogg ${ }^{\text {a }}$ & 3.88 & 5.32 \\
\hline Adidas & 2.56 & 3.34 \\
\hline Duracell & 2.51 & 3.13 \\
\hline L'Oreal & 2.51 & 3.53 \\
\hline Phillips & 2.38 & 2.81 \\
\hline Nivea & 2.23 & 2.32 \\
\hline IKEA & 2.14 & 1.51 \\
\hline Nokia & N/A & 2.86 \\
\hline Nescafe & N/A & 2.74 \\
\hline Renault & N/A & 1.21 \\
\hline Danone & $\mathrm{N} / \mathrm{A}$ & 1.90 \\
\hline
\end{tabular}

(positivity and negativity both $<4$ ). The final sample included 215 participants (50.2\% females), aged 18 to 66 , with a mean age of 41 .

\subsection{Instrument}

Participants were told that the study included two questionnaires. The first one focused on brands. Data were collected for 14 brands, including the seven brands comprising the American brand index and seven non-American filler brands. The order of the brands was randomized. As in the pre-test, the WTB index $(\alpha=0.89)$ included two measures for each of the seven brands: frequency of consumption and future purchase intent. Participants also rated how they felt toward each brand, from 1 (very negative) to 7 (very positive), and the measures relating to the seven American brands formed the brand attitude index $(\alpha=0.86)$.

In the second questionnaire, objective ambivalence was assessed by having participants indicate their level of agreement with a series of 20 statements, half 
addressing positive views of the USA and half negative, using the same format as in the pre-test: seven-point Likert scales (see positivity and negativity measures in the "Appendix"). As in the pre-test, subjective ambivalence was assessed by asking participants to indicate the degree to which (1-not at all to 7-extremely 7) each of nine randomly presented adjectives described their general opinion about the USA; "divided", "ambivalent", and "mixed" measured felt ambivalence (Cacioppo et al. 1997; Priester and Petty 1996).

\subsection{Objective and subjective ambivalence measures}

Positivity and negativity scores were computed as the mean of the positive/negative items. These scales yielded acceptable reliability ( $\alpha=0.88$ and 0.87 , respectively). In line with the recruiting strategy, the sample provided variance in both positivity $(M=$ $4.14 ; \mathrm{SD}=1.24)$ and negativity $(M=4.78 ; \mathrm{SD}=1.30)$. There was no correlation between positivity and negativity $(r=-0.05$, n.s.) reiterating the orthogonality of the two dimensions. The objective measure of ambivalence was computed based on Priester and Petty's (1996) GTM and ranged from -1.40 to 8.88 ( $M=6.71 ; \mathrm{SD}=1.36)$. The subjective measure of ambivalence was computed as the mean on the three items $(\alpha=0.84)$ and provided variance in the sample $(M=3.85 ; \mathrm{SD}=1.49)$. As in the pre-test, the correlation between the objective (GTM) and subjective ambivalence measures was significant but small $(r=0.25, p<0.05)$, consistent with previous research (Newby-Clark et al. 2002; Priester and Petty 1996; Thompson et al. 1995).

\section{Results}

The WTB index was computed by averaging the two measures of purchase behavior (past purchase and future purchase intention, $r=0.86, p<0.05$ ) across the seven emblematic US brands. The index was regressed, in an ordinary least squares hierarchical analysis, against positivity and negativity in a first step and the objective and subjective measures of ambivalence were added in a second step. To isolate the effect of ambivalence on WTB, the brand attitude measure was included in the regressions. Age and gender were also included as control variables because previous research has sometimes shown a relationship between animosity and these variables (Klein et al. 1998; Klein 2002). All variables were mean-centered.

In addition to the significance of the beta coefficients, the statistical significance of the increase in explained variance resulting from the addition of ambivalence in the second step is considered. The regression results (see Table 2) reveal a significant negative beta coefficient for objective ambivalence and significant statistical improvements with the inclusion of the ambivalence variables (the statistical improvement is also significant without the subjective ambivalence measure included in the model). Objective ambivalence toward a country is negatively related to consumers' WTB brands emblematic of that country, and this effect occurs independently of the impact of positivity and negativity alone. The results further show that only objective ambivalence is negatively related to WTB. The subjective measure of ambivalence is not significant. 
Table 2 Multiple regression results: willingness to buy emblematic brands

\begin{tabular}{|c|c|c|c|c|}
\hline & \multicolumn{2}{|l|}{ Model 1} & \multicolumn{2}{|l|}{ Model 2} \\
\hline & Standard $\beta$ & $t$ value & Standard $\beta$ & $t$ value \\
\hline Positivity & $0.14^{*}$ & 2.69 & $0.32 *$ & 4.34 \\
\hline Negativity & -0.07 & -1.38 & -0.03 & -0.43 \\
\hline Age & $-0.14^{*}$ & -2.79 & $-0.16^{*}$ & -3.21 \\
\hline Gender & -0.01 & -0.17 & -0.02 & -0.48 \\
\hline Brand attitude & $0.59^{*}$ & 10.72 & $0.62 *$ & 11.38 \\
\hline Subjective ambivalence & & & 0.08 & 1.47 \\
\hline Objective ambivalence (GTM) & & & $-0.26^{*}$ & -3.38 \\
\hline Adjusted $R^{2}$ & 0.50 & & $0.52 * *$ & \\
\hline
\end{tabular}

$* p<.05$

$* * \Delta \mathrm{R}^{2}$ significant, $p<.05$

\section{Discussion}

This study reveals important dynamics overlooked in previous research. Whereas previous research has adopted a univalent approach to $\mathrm{CoO}$ effects, these results indicate that the ambivalence that results from the coexistence of positive and negative views of a country should be taken into account. The study shows that not only are positivity and negativity toward a country distinct constructs, each affecting consumers' WTB emblematic brands separately, but that their relationship to consumers' purchases is interactive: Consumers who harbor both positive and negative views of a country are less willing to purchase emblematic brands from that country. Thus, as in Otnes et al. (1997), purchase resistance appears to serve as one of the behavioral strategies to cope with ambivalence.

A further finding and contribution relates to the apparently latent nature of ambivalence and the automatic nature of the avoidance behaviors it triggers. While previous research on ambivalence has pointed to the distinction between subjective and objective measures of the construct and noted that the two measures of ambivalence only have a small correlation (Thompson et al. 1995; Priester and Petty 1996), this is the first study to also document their differential predictive validity and to propose the objective computation of ambivalence scores, such as with the GTM measure, as a more suited instrument to capture the construct and its effects. The findings highlight the difficulty of assessing the subjective experience of the ambivalence state and the importance and practicality of using more indirect measures. This latent nature of ambivalence warrants further research and suggests that other indirect measures such as implicit attitude tests could shed further light on its structure and impact.

A related opportunity for future research lies in the potential to experimentally activate negative, positive, or even ambivalent country-relevant information to assess the impact of making salient different dimensions of the country attitude on consumers' judgments and choices (Hong and Kang 2006). The interplay between positive and negative country views could be studied by activating different subsets 
of country feelings (Briley and Wyer 2002) and, in turn, assessing whether priming ambivalence affects consumer choices away from products of that culture (Russell and Russell 2006) or instead triggers a corrective mechanism (Dasgupta and Greenwald 2001).

Of course, this study's results are bounded by the fact that positivity, negativity, and therefore ambivalence were measured and not manipulated; hence, the nature of the data does not allow full control over the context and assessments of causality. With a few exceptions (e.g., Otnes et al. 1997), existing research on ambivalence has relied on experimental settings, where participants are presented with information about a new product or attitude object (Jonas et al. 1997) or where the context is changed to create more or less ambivalence (Priester et al. 2007; Zemborain and Johar 2007). Notwithstanding the limitations, investigating ambivalence outside of the laboratory in naturally occurring situations enhances external validity and adds to the growing body of knowledge on the topic by complementing previous laboratory-based experiments.

This research extends previous work by providing evidence that consumers' views of a country are related to the consumption of brands emblematic of that country. The study's findings have managerial implications for US businesses and policymakers alike. Previous animosity research has encouraged managers to measure negative views of the producing country as an aid in making decisions about the promotion of the "made in" label of their products (Klein et al. 1998). The present research suggests that brand tracking studies should include measures of how strongly a brand is associated with its home country, as well as separate measures capturing positive and negative views toward the home country.

Finally, the finding that ambivalence toward a country is detrimental to the purchases of brands from that country suggests that companies should attempt to reduce consumers' ambivalence. Recent research documented that because ambivalent people are motivated to reduce their ambivalence, they process information related to the attitude object systematically and thus need stronger arguments to be persuaded (Cavazza and Butera 2008). Research also found that ambivalent individuals pay closer attention to agreeable messages and avoid processing disagreeable information (Clark et al. 2008). Ambivalence resolution is thus a fruitful avenue for future research (van Harreveld et al. 2009).

Open Access This article is distributed under the terms of the Creative Commons Attribution Noncommercial License which permits any noncommercial use, distribution, and reproduction in any medium, provided the original author(s) and source are credited.

\section{Appendix: Measures of positivity and negativity toward the USA}

Positivity:

I appreciate American culture.

America is creative in the musical and cinematographic domain.

There are many good things about American culture. 
The US encourages entrepreneurship.

The American model of capitalism promotes a strong economy.

France and the US are good economic partners.

America makes one dream.

The US encourages creativity and innovation.

The economic success of the US benefits France.

The American economic growth is remarkable.

Negativity:

American culture is too present.

American influence threatens French culture.

The US has a lot of economic influence in France.

France is fairer in its trade with the US than the US is with France.

American capitalism contributes to social injustice.

The policies of the US in Iraq are bad.

The US constantly ignores France's positions in international affairs.

The US thinks it is the police of the world.

The US has a bad environmental record.

The US pursues its economic interests at the expense of France.

\section{References}

Aaker, D. A. (1991). Managing brand equity: capitalizing on the value of a brand name. New York: Free.

Amodio, D. M., \& Devine, P. G. (2006). Stereotyping and evaluation in implicit race bias: Evidence for independent constructs and unique effects on behavior. Journal of Personality and Social Psychology, $91,652-661$.

Back, M. D., Schmukle, S. C., \& Egloff, B. (2009). Predicting actual behavior from the explicit and implicit self-concept of personality. Journal of Personality and Social Psychology, 97(3), 533-548.

Banaji, M. R., \& Greenwald, A. G. (1994). Implicit stereotyping and prejudice. In M. Zanna \& J. Olson (Eds.), The psychology of prejudice: The Ontario symposium 7 (pp. 55-76). Hillsdale: Erlbaum.

Berman, R. (2005). Americanization and anti-Americanism. In A. Stephan (Ed.), Americanization and anti-Americanism: The German encounter with American culture after 1945 (pp. 11-24). New York: Berghahn Books.

Breckler, S. J. (1994). A comparison of numerical indexes for measuring attitude ambivalence. Educational and Psychological Measurement, 54(2), 350-365.

Briley, D., \& Wyer, R. (2002). The effect of group membership salience on the avoidance of negative outcomes: Implications for social and consumer decisions. Journal of Consumer Research, 29(3), 400-415.

Cacioppo, J. T., Gardner, W. L., \& Berntsen, G. G. (1997). Attitudes and evaluative space: beyond bipolar conceptualizations and measures: The case of attitudes and evaluative space. Personality and Social Psychology Review, 1(1), 3-25.

Cavazza, N., \& Butera, F. (2008). Bending without breaking: Examining the role of attitudinal ambivalence in resisting persuasive communication. European Journal of Social Psychology, 38(1), 1-15.

Clark, J., Wegener, D., \& Fabrigar, L. (2008). Attitudinal ambivalence and message-based persuasion: Motivated processing of proattitudinal information and avoidance of counterattitudinal information. Personality and Social Psychology Bulletin, 34(4), 565-577.

Dasgupta, N., \& Greenwald, A. (2001). On the malleability of automatic attitudes: Combating automatic prejudice with images of admired and disliked individuals. Journal of Personality and Social Psychology, 81, 800-814.

Diamantopoulos, A., \& Winklhofer, H. M. (2001). Index construction with formative indicators: An alternative to scale development. Journal of Marketing Research, 38(2), 269-277. 
Federico, C. M. (2006). Ideology and the affective structure of whites' racial perceptions. Public Opinion Quarterly, 70(3), 327-353.

Festinger, L. (1957). A theory of cognitive dissonance. Evanston, IL: Row, Peterson.

GMI (2005). GMI poll press releases. http://www.gmi-mr.com/gmipoll/pr-archive.php. Accessed 15 Mar 2008.

Goldberg, M. E., \& Baumgartner, H. E. (2002). Cross-country attraction as a motivation for product consumption. Journal of Business Research, 55(11), 901-906.

Gürhan-Canli, Z., \& Maheswaran, D. (1994). Determinants of country of origin evaluations. Journal of Consumer Research, 27, 96-108.

Has, R. G., Katz, I., Rizzo, N., Bailey, J., \& Moore, L. (1991). Cross-racial appraisal as related to attitude ambivalence and cognitive complexity. Personality and Social Psychology Bulletin, 17(1), 83-92.

Hass, R. G., Katz, I., Rizzo, N., Bailey, J., \& Eisenstadt, D. (1992). When racial ambivalence evokes negative affect, using a disguised measure of mood. Personality and Social Psychology Bulletin, 18, 786-797.

Hatch, M. J., \& Rubin, J. (2006). The hermeneutics of branding. Journal of Brand Management, 14(1/2), 40-59.

Heider, F. (1946). Attitudes and cognitive organization. The Journal of Psychology, 21, 107-112.

Holt, D. (2004). How brands become icons: The principles of cultural branding. Cambridge: Harvard Business School.

Hong, S. T., \& Kang, D. K. (2006). Country-of-origin influences on product evaluations: The impact of animosity and perceptions of industriousness brutality on judgments of typical and atypical products. Journal of Consumer Psychology, 16(3), 232-239.

Hong, S. T., \& Wyer, R. S. (1989). Effects of country-of-origin and product-attribute information on product evaluation: An information processing perspective. Journal of Consumer Research, 16, 175187.

Hong, S. T., \& Wyer, R. S. (1990). Determinants of product evaluation: Effects of the time interval between knowledge of a product's country of origin and information about its specific attributes. Journal of Consumer Research, 17, 277-288.

Interbrand (2006). Best global brands. http://www.interbrand.com/best_brands_2006.asp. Accessed 11 Jan 2007.

Johansson, J. K. (1989). Determinants and effects of the use of 'made in' labels. International Marketing Review, 6(1), 47-58.

Johansson, J. K., Douglas, S. P., \& Nonaka, I. (1985). Assessing the impact of country of origin on product evaluations: A new methodological perspective. Journal of Marketing Research, 23, 388396.

Jonas, K., Diehl, M., \& Bromer, P. (1997). Effects of attitudinal ambivalence on information processing and attitude-intention consistency. Journal of Experimental Social Psychology, 33(2), 190-210.

Kaplan, K. J. (1972). On the ambivalence-indifference problem in attitude theory and measurement: A suggested modification of the semantic differential technique. Psychological Bulletin, 77, 361-372.

Katz, I. (1981). Stigma: A social psychological analysis. Hillsdale: Erlbaum.

Katz, L., \& Hass, R. G. (1988). Racial ambivalence and American value conflict: Correlational and priming studies of dual cognitive structures. Journal of Personality and Social Psychology, 55, 893905 .

Katzenstein, P. J., \& Keohane, R. O. (2007). Varieties of anti-Americanism: A framework for analysis. In P. J. Katzenstein \& R. O. Keohane (Eds.), Anti-Americanisms in world politics (pp. 9-38). Ithaca: Cornell University Press.

Kinder, D. R., \& Sears, D. O. (1981). Prejudice and politics: Symbolic racism versus racial threats to the good life. Journal of Personality and Social Psychology, 40(3), 414-431.

Klein, J. G. (2002). US versus them, or us versus everyone? Delineating consumer aversion to foreign goods. Journal of International Business Studies, 33(2), 345-363.

Klein, J. G., Ettenson, R. E., \& Morris, M. D. (1998). The animosity model of foreign product purchase: An empirical test in the People's Republic of China. Journal of Marketing, 62, 89-100.

Kuehn, K. (2005). Managing the brand in an age of anti-Americanism. Executive Speeches, 19(4), $28-33$.

Larsen, J., McGraw, A. P., \& Cacioppo, J. (2001). Can people feel happy and sad at the same time? Journal of Personality and Social Psychology, 81(4), 684-696.

Lau-Gesk, L. (2005). Understanding consumer evaluations of mixed affective experiences. Journal of Consumer Research, 32, 23-28.

Leclerc, F., Schmitt, B., \& Dube, L. (1994). Foreign branding and its effects on product perceptions and attitudes. Journal of Marketing Research, 31, 263-270. 
Li, W. K., \& Wyer, R. S. (1994). The role of country-of-origin in product evaluation: Informational and standard of comparison effects. Journal of Consumer Psychology, 3(2), 187-212.

Locke, K., \& Braun, C. (2009). Ambivalence versus valence: Analyzing the effects of opposing attitudes. Social Cognition, 27(1), 89-104.

Luce, M. F. (1998). Choosing to avoid: Coping with negatively emotion-laden consumer decisions. Journal of Consumer Research, 24, 409-433.

Maio, G. R., Esses, V. M., \& Bell, D. W. (2000). Examining conflict between components of attitudes: Ambivalence and inconsistency are distinct constructs. Canadian Journal of Behavioural Science, 32 (2), 71-83.

Newby-Clark, I. R., McGregor, I., \& Zanna, M. P. (2002). Thinking and caring about cognitive inconsistency: When and for whom does attitudinal ambivalence feel uncomfortable? Journal of Personality and Social Psychology, 82(2), 157-166.

Nijssen, E. J., \& Douglas, S. P. (2004). Examining the animosity model in a country with a high level of foreign trade. International Journal of Research in Marketing, 21(1), 23-38.

Otnes, C., Lowrey, T. M., \& Shrum, L. J. (1997). Toward an understanding of consumer ambivalence. Journal of Consumer Research, 24, 80-93.

Ouellet, J. (2007). Consumer racism and its effects on domestic cross-ethnic product purchase: An empirical test in the United States, Canada, and France. Journal of Marketing, 71(1), 113-128.

Papadopoulos, N., \& Heslop, L. A. (1993). Product-country images: Impact and role in international marketing. New York: International Business.

Peabody, D. (1985). National characteristics. Cambridge: Cambridge University Press.

Pharr, J. M. (2005). Synthesizing country-of-origin research from the last decade: Is the concept still salient in an era of global brands? Journal of Marketing Theory and Practice, 13(4), 34-45.

Priester, J. R., \& Petty, R. E. (1996). The gradual threshold model of ambivalence: Relating the positive and negative bases of attitudes to subjective ambivalence. Journal of Personality and Social Psychology, 71(3), 431-449.

Priester, J. R., Petty, R. E., \& Park, K. (2007). Whence univalent ambivalence: From the anticipation of conflicting reactions. Journal of Consumer Research, 34, 11-21.

Riefler, P., \& Diamantopoulos, A. (2007). Consumer animosity: A literature review and a reconsideration of its measurement. International Marketing Review, 24(1), 87-119.

Roger, P. (2005). The American enemy: A story of French anti-Americanism. Chicago: The University of Chicago Press.

Russell, D. W., \& Russell, C. A. (2006). Explicit and implicit catalysts of consumer resistance: The effects of animosity, cultural salience and country of origin on subsequent choice. International Journal of Research in Marketing, 23(3), 321-331.

Sardar, Z., \& Davies, M. W. (2003). Why do people hate America? London: Icon Books.

Spiggle, S. (1994). Analysis and interpretation of qualitative data in consumer research. Journal of Consumer Research, 21, 491-503.

Strack, F., \& Deutsch, R. (2004). Reflective and impulsive determinants of social behavior. Personality and Social Psychology Review, 8, 220-247.

Thakor, M. V. (1996). Brand origin: Conceptualization and review. The Journal of Consumer Marketing, 13(3), 27-42.

Thompson, M. M., Zanna, M. P., \& Griffin, D. W. (1995). Let's not be indifferent about (attitudinal) ambivalence. In R. E. Petty \& J. A. Krosnick (Eds.), Attitude strength: Antecedents and consequences (pp. 361-386). Mahwah: Erlbaum.

Tormala, Z., \& DeSensi, V. (2008). The perceived informational basis of attitudes: Implications for subjective ambivalence. Personality and Social Psychology Bulletin, 34(2), 275-287.

van Harreveld, F., van der Pligt, J., \& de Liver, Y. (2009). The agony of ambivalence and ways to resolve it: Introducing the maid model. Personality and Social Psychology Review, 13(1), 45-51.

Williams, P., \& Aaker, J. (2002). Can mixed emotions peacefully co-exist? Journal of Consumer Research, 28, 636-649.

World Public Opinion. (2009). Though Obama viewed positively, still much criticism of US foreign policy: Global poll. http://www.worldpublicopinion.org/pipa/articles/views_on_countriesregions_bt/ 623.php. Accessed 7 Jul 2009.

Zemborain, M., \& Johar, G. V. (2007). Attitudinal ambivalence and openness to persuasion: A framework for interpersonal influence. Journal of Consumer Research, 33, 506-514.

Zogby International (2005). Report on corporate and foreign policy: Expert interviews. http://www. businessfordiplomaticaction.org/learn/research.php. Accessed 15 Dec 2007. 